Louisiana State University

LSU Digital Commons

$11-1-2008$

\title{
Central blockade of oxytocin receptors during mid-late gestation reduces amplitude of slow afterhyperpolarization in supraoptic oxytocin neurons
}

\author{
R. Teruyama \\ University of Tennessee Health Science Center \\ D. L. Lipschitz \\ The University of Utah \\ L. Wang \\ University of Tennessee Health Science Center \\ G. R. Ramoz \\ The University of Utah \\ W. R. Crowley \\ The University of Utah
}

See next page for additional authors

Follow this and additional works at: https://digitalcommons.Isu.edu/biosci_pubs

\section{Recommended Citation}

Teruyama, R., Lipschitz, D., Wang, L., Ramoz, G., Crowley, W., Bealer, S., \& Armstrong, W. (2008). Central blockade of oxytocin receptors during mid-late gestation reduces amplitude of slow afterhyperpolarization in supraoptic oxytocin neurons. American Journal of Physiology - Endocrinology and Metabolism, 295 (5) https://doi.org/10.1152/ajpendo.90620.2008 


\section{Authors}

R. Teruyama, D. L. Lipschitz, L. Wang, G. R. Ramoz, W. R. Crowley, S. L. Bealer, and W. E. Armstrong 


\title{
Central blockade of oxytocin receptors during mid-late gestation reduces amplitude of slow afterhyperpolarization in supraoptic oxytocin neurons
}

\author{
R. Teruyama, ${ }^{1}$ D. L. Lipschitz, ${ }^{2}$ L. Wang, ${ }^{1}$ G. R. Ramoz, ${ }^{2}$ W. R. Crowley, ${ }^{2}$ S. L. Bealer, ${ }^{2}$ \\ and W. E. Armstrong ${ }^{1}$ \\ ${ }^{1}$ Department of Anatomy and Neurobiology, University of Tennessee, Health Science Center, Memphis, Tennessee; \\ and ${ }^{2}$ Department of Pharmacology and Toxicology, University of Utah, Salt Lake City, Utah
}

Submitted 21 July 2008; accepted in final form 23 September 2008

Teruyama R, Lipschitz DL, Wang L, Ramoz GR, Crowley WR, Bealer SL, Armstrong WE. Central blockade of oxytocin receptors during mid-late gestation reduces amplitude of slow afterhyperpolarization in supraoptic oxytocin neurons. Am J Physiol Endocrinol Metab 295: E1167-E1171, 2008. First published September 23, 2008; doi:10.1152/ajpendo.90620.2008.-The neurohypophysial hormone oxytocin (OT), synthesized in magnocellular paraventricular (PVN) and supraoptic (SON) nuclei, is well known for its effects in lactation. Our previous studies showed that central OT receptor (OTR) binding is increased during gestation and that blockade of central OTRs, specifically during mid-late gestation, causes a delay in OT release during suckling and reduces weight gain in pups, suggesting decreased milk delivery. In the present study, we tested whether central OTR blockade during late gestation disrupts the gestation-related plasticity in intrinsic membrane properties. Whole cell current-clamp recordings were performed in OT neurons from pregnant rats (19-22 days in gestation) that were infused with an OTR antagonist (OTA) or artificial cerebrospinal fluid (aCSF) and from virgin rats infused with aCSF into the third ventricle via an osmotic minipump beginning on days $12-14$ of gestation. The amplitudes of both $\mathrm{Ca}^{2+}$-dependent afterhyperpolarizations (AHPs), an apamin-sensitive medium AHP (mAHP) and an apamin-insensitive slow AHP (sAHP), were significantly increased during late gestation in control pregnant animals. However, the amplitude of the sAHP from pregnant rats treated with the OTA was significantly smaller than that of pregnant control rats and similar to that of virgins. These results indicate that the diminished efficiency in lactation due to OTR blockade may be partly a result of an altered sAHP that would shape OT bursting. These findings suggest that central actions of OT during late gestation are necessary for programming the plasticity of at least some of the intrinsic membrane properties in OT neurons during lactation.

vasopressin; electrophysiology; hypothalamus; lactation; hyperpolarizing afterpotentials

THE NEUROHYPOPHYSIAL HORMONES OXytocin (OT) and vasopressin (VP) are synthesized in the magnocellular cells (MNCs) located in the hypothalamic supraoptic (SON) and paraventricular (PVN) nuclei. These hormones are released into the systemic circulation from the neurohypophysis in response to physiological demands, such as milk ejection and parturition for OT $(14,30)$ and osmotic and cardiovascular challenge for VP (31). The release of OT is determined by the rate and pattern of neuronal activity of SON and PVN neurons (31). During lactation, OT neurons display a short (2-4 s), highfrequency (up to $80 \mathrm{~Hz}$ ) burst of action potentials shortly before each milk ejection. This bursting activity is synchronized among all OT neurons (4) and results in a bolus release

Address for reprint requests and other correspondence: R. Teruyama, Dept of Anatomy and Neurobiology, Univ. of Tennessee, Health Science Center, 855 Monroe Ave., Memphis, TN 38163 (e-mail: rteruyam@utmem.edu). of OT into the bloodstream. This pulsatile OT release into the general circulation is believed to maximize the biological effects of OT (6) and is requisite for milk ejection $(17,33,36)$.

The firing patterns of MNCs are critically modulated by intrinsic membrane properties, such as the $\mathrm{Ca}^{2+}$-dependent afterhyperpolarizations (AHPs) and the $\mathrm{Ca}^{2+}$-dependent depolarizing afterpotentials (DAPs). Both AHPs and DAPs are specifically enhanced during lactation (37-39), indicating that these changes interact with the expression of the specific firing pattern of OT neurons. Moreover, these changes are installed during late pregnancy (38), suggesting that OT neurons transform their intrinsic properties before their increased activity during parturition and suckling.

In addition to release into the general circulation, somatodendritic release of OT within the SON and PVN is observed during parturition and lactation $(2,19,26-29,34)$. Central infusion of a selective OT receptor antagonist (OTA) during the final $2 \mathrm{wk}$ of gestation delayed the pulsatile release of OT during suckling and impaired pup development during lactation, even though the OTA had been removed (21). Furthermore, we recently demonstrated (3) that OT receptor (OTR) binding in the PVN and SON is significantly increased during mid- to late gestation. These data suggest that increased OTR binding and OTR stimulation during gestation is critical for determining the response characteristics of OT release during parturition and lactation. In addition, central OT $(24,25,41)$ has been implicated in the OT neuronal-glia morphological plasticity characteristic of late pregnancy and lactation (16, 40). Therefore, the present study was conducted to evaluate the effect of central blockade of OTR on the plasticity of intrinsic membrane properties of OT neurons during late gestation (37).

\section{MATERIALS AND METHODS}

Animals. Timed-pregnant and virgin (age matched) Sprague-Dawley rats were used (Charles River Laboratories, Wilmington, MA). The rats were housed individually in a room on a 12:12-h light-dark cycle with access to food and water available ad libitum. The animals received surgery at the University of Utah and were then transferred to the University of Tennessee for the electrophysiological experiment by overnight shipment. Before the study, the potential for stress of surgery and subsequent shipment was tested. Animals $(n=14)$ that received surgery on gestation day 13 were shipped overnight airfreight to Tennessee on gestation day 15. The lengths of gestation, litter sizes, and mean pup weights were similar to values routinely observed in our laboratory. The Institutional Animal Care and Use

The costs of publication of this article were defrayed in part by the payment of page charges. The article must therefore be hereby marked "advertisement" in accordance with 18 U.S.C. Section 1734 solely to indicate this fact. 
Committees at the University of Tennessee and the University of Utah approved all protocols.

Surgery. Alzet osmotic minipumps (Durect, Cupertino, CA; model 2002, pump rate $=0.5 \mu \mathrm{l} / \mathrm{h}$ ) were filled with either the OTA desGly- $\mathrm{NH}_{2}-\mathrm{d}\left(\mathrm{CH}_{2}\right)_{5}\left[\mathrm{D}-\mathrm{Tyr}^{2}\right.$, Thr $\left.{ }^{4}\right]$ OVT $(200 \mathrm{ng} / \mu \mathrm{l}$, gift of $\mathrm{M}$. Manning, Medical University of Ohio, Toledo, $\mathrm{OH}$ ) or vehicle [artificial cerebrospinal fluid (aCSF) containing (in mM) 126.5 $\mathrm{NaCl}, 4 \mathrm{KCl}, 0.5 \mathrm{KH}_{2} \mathrm{PO}_{4}, 1.1 \mathrm{CaCl}_{2}, 0.83 \mathrm{MgCl}_{2}, 0.5 \mathrm{Na}_{2} \mathrm{SO}_{4}$, and $2.5 \mathrm{D}$-glucose, $\mathrm{pH}=7.2$ ]. Rats were anesthetized with 2,2,2tribromoethanol (Avertin, Sigma-Aldrich, St. Louis, MO; 300 $\mathrm{mg} / \mathrm{kg}$ ) on days $12-14$ of gestation and placed in a stereotaxic instrument. The scalp was incised and retracted laterally, and the skull was leveled between lambda and bregma. A 2-mm opening through the skull was drilled $0.4 \mathrm{~mm}$ posterior to bregma, along the midline. A stainless steel cannula (22 gauge) was inserted to a depth of $8.0 \mathrm{~mm}$ from the surface of the skull into the third ventricle. The osmotic pump was then inserted subcutaneously between the scapulae and connected to the cannula with polyethylene tubing. The cannula was secured with small screws placed in the skull and dental acrylic, which covered the exposed area. Virgin rats received only vehicle.

Electrophysiology. The rats in late gestation (19-22 days) were deeply anesthetized with pentobarbital sodium $(50 \mathrm{mg} / \mathrm{kg}$ ip $)$ and perfused through the heart with cold aCSF in which $\mathrm{NaCl}$ was replaced by an equiosmolar amount of sucrose. Brains were removed, and coronal slices $(250 \mu \mathrm{m})$ containing SON were obtained. Slices were maintained in aCSF, bubbled continuously with $95 \% \mathrm{O}_{2}-5 \% \mathrm{CO}_{2}$, containing (in $\mathrm{mM}$ ) $124 \mathrm{NaCl}, 3 \mathrm{KCl}, 2.0 \mathrm{CaCl}_{2}$, $1.3 \mathrm{MgCl}_{2}, 1.24 \mathrm{NaH}_{2} \mathrm{PO}_{4}, 25 \mathrm{NaHCO}_{3}, 0.2$ ascorbic acid, and 10 D-glucose ( $\mathrm{pH}$ 7.4). Slices were stored at room temperature before recording. Whole cell patch-clamp recordings were acquired with an Axopatch 200B or 700A (Axon Instruments, Foster City, CA) amplifier and a Windows-platform PC. The MNCs in the SON were visually identified with an Olympus BX50WI microscope with a $\times 40$ water immersion lens $(0.8$ numerical aperture) under infrared illumination $(780 \pm 30 \mathrm{~nm})$ and a charge-coupled device camera. Recordings were taken with borosilicate electrodes (4- to 8-M $\Omega$ resistance) produced with a horizontal electrode puller (Sutter Instruments) and filled with a patch solution containing (in mM) $135 \mathrm{KMeSO}_{4}, 8 \mathrm{KCl}, 1 \mathrm{MgCl}_{2}, 10 \mathrm{HEPES}, 2$ adenosine 5 '-triphosphate (ATP), 0.4 guanosine 5 '-triphosphate (GTP), and 0.2 EGTA. The intracellular solutions also contained $0.2 \% \mathrm{~N} \varepsilon$ biotinyl-L-lysine (Biocytin; Sigma, St. Louis, MO) to identify the patched cell (see Immunocytochemistry).

Immunocytochemistry. The recorded neurons were identified with double-labeling immunofluorescence (Fig. 1). The anti-VP antibody was raised in rabbit against VP-neurophysin (VP-NP; provided by Alan Robinson, University of Pittsburgh, Pittsburgh, PA) and used at a 1:20,000 dilution. An anti-OT-NP antibody (PS36 or PS38) was raised in mouse (provided by Harold Gainer and Mark Whitnall, National Institutes of Health) and used at a 1:500 dilution. The slices were incubated $48-72 \mathrm{~h}$ at $4^{\circ} \mathrm{C}$, followed by incubation in a cocktail of secondary antibodies and avidin-7-amino-4-methylcoumarin-3- acetic acid (AMCA) (Vector Laboratories, Burlingame, CA) overnight at $4^{\circ} \mathrm{C}$. The secondary antibodies used were fluorescein isothiocyanate (FITC)-conjugated goat anti-rabbit (Vector Laboratories) and Alexa Fluor 594-conjugated goat anti-mouse IgG (Invitrogen, Carlsbad, CA). Avidin-AMCA was used to visualize the recorded cells. All numerical data were statistically analyzed with ANOVA and are presented as means \pm SE. Post hoc analysis was assessed with Scheffé's test. Differences were considered statistically significant at $P<0.05$.

\section{RESULTS}

The AHPs were evoked by a train of 20 action potentials evoked by brief depolarizing pulses $(5 \mathrm{~ms}, 0.25 \mathrm{nA})$ at $20 \mathrm{~Hz}$. Because the expression of AHPs is dependent upon the number and frequency of action potentials $(13,15,18)$, a fixed number of action potentials at a fixed frequency was used to generate AHPs for equitable comparisons. The train of action potentials was followed by two distinct major AHP components, the medium (mAHP) and the slow AHP (sAHP), in MNCs (Fig. 2A). The mAHP has a duration of 200-500 $\mathrm{ms}$ and is blocked by apamin $(1,7,15,39)$, suggesting the involvement of $\mathrm{Ca}^{2+}$-activated small-conductance $\mathrm{K}^{+}(\mathrm{SK})$ channels $(35)$. The sAHP is indicated by a deceleration of the decay of the AHPs (Fig. 2A), and its channel type is undetermined.

The average total area of AHPs was significantly larger in OT neurons from pregnant animals receiving vehicle, similar to the plasticity previously observed (38) (Fig. 2B). However, the area of AHPs among OT neurons in pregnant rats that received central OTA was significantly smaller than that from control pregnant rats and did not differ from that in virgin rats (Fig. 2B). The amplitudes of both mAHP and sAHP were significantly larger during pregnancy in OT neurons (Fig. 2, $C$ and $D$ ). While the enhanced amplitude of the sAHP in OT neurons during pregnancy was significantly attenuated by the OTA, the enhanced amplitude of mAHP in OT neurons from the OTA rats did not differ from those in either control pregnant or virgin rats. In contrast to OT neurons, the total area of AHPs and the amplitudes of the mAHP and sAHP in VP neurons were not affected by either pregnancy or central OTA (Fig. 3).

A subset of OT neurons was treated with bath application of apamin, to assess the effect of OTA on the sAHP alone. As predicted, bath application of apamin blocked the mAHP and therefore isolated the SAHP (Fig. 4A). In accordance with the amplitude of the sAHP, the area of the isolated sAHP in OT neurons from control pregnant rats was significantly larger than that from virgin rats, and the central application of OTA significantly suppressed the area of sAHP (Fig. 4B). Interest-
Patched Neuron

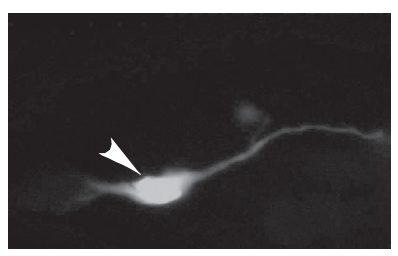

OT-NP ir-neurons

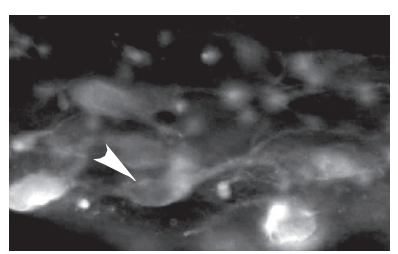

VP-NP ir-neurons

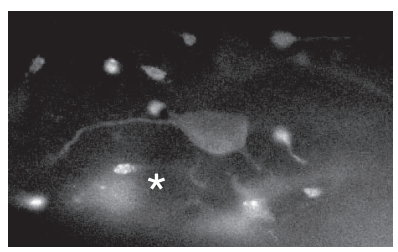

Fig. 1. Immunocytochemical identification of cell types in magnocellular cells (MNCs) from SON. The patched cell was filled with Biocytin and visualized with avidin-7-amino-4-methylcoumarin-3-acetic acid (AMCA) (arrowhead, left). The tissue was then labeled for oxytocin (OT)- and vasopressin (VP)-neurophysins (NP) by double immunofluorescence using Alexa Fluor 594- and FITC-conjugated secondary antibodies, respectively. The recorded cell was immunoreactive (IR) to OT-NP (arrowhead, center) but not to VP-NP (asterisk, right). 
A Control Pregnant OTA Pregnant

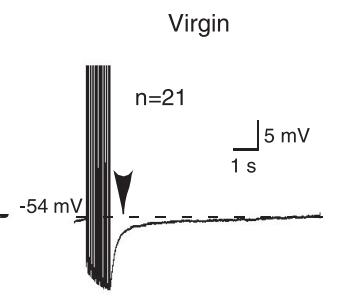

Superimposed
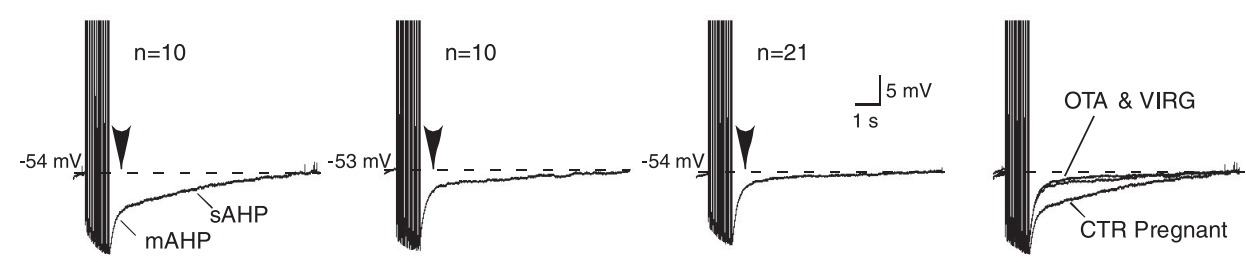

B

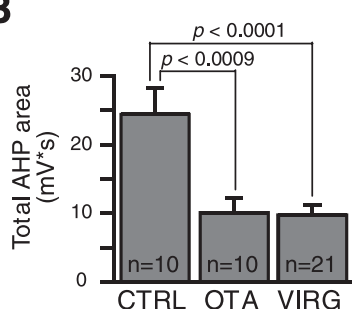

C

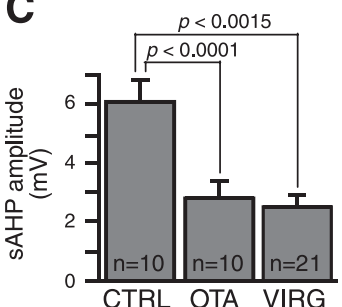

D

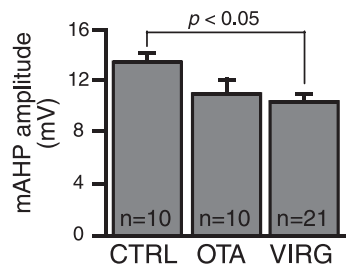

Fig. 2. Afterhyperpolarizations (AHPs) in OT neurons. A: from left to right, averaged traces of AHPs from recorded OT neurons in control pregnant (Ctrl), pregnant with OT receptor (OTR) antagonist (OTA), and virgin (Virg) animals. Far right: traces from each group are superimposed. AHPs were generated by a train of action potentials (truncated) evoked by 20 brief depolarizing pulses at $20 \mathrm{~Hz}$. An abrupt deceleration in the decay of AHPs distinguishes the medium (mAHP) and slow (sAHP) AHPs. Arrowheads indicate location where peak sAHP amplitudes were measured. B: the average area of the total AHP is significantly higher during pregnancy. However, central blockade of OTR significantly attenuated the expression of the AHP during pregnancy. $C$ : the average amplitude of the sAHP is significantly higher during pregnancy, and this effect is blocked by the OTA. $D$ : the effect of central blockade of OTR on mAHP is ambiguous, since the average amplitude of mAHP in OTA animals did not differ from those in either Ctrl or Virg animals.

ingly, all five OT neurons treated with apamin from control pregnant rats showed further increase in area of the sAHP after bath application of apamin (Fig. 4, $C$ and $D$ ). Indeed, the area of sAHP exceeded the total area of AHPs before the application of apamin in all cases $(n=5)$ from pregnant rats. In contrast, no such enhancement by apamin was observed in the five OT neurons tested with OTA, or in the majority (11 of 12) of virgin rats.

Finally, to ensure that the effects of OTA on AHPs were not due to the persistent antagonism of OTR after preparation of brain slices, bath applications of OTA $(1 \mu \mathrm{M})$ were tested on OT neurons $(n=7)$ in slices from additional pregnant animals (days 19-21). The amplitude of sAHP in OT neurons before and after the application of OTA was $4.50 \pm 1.0$ and $4.99 \pm$ $1.52 \mathrm{mV}$, respectively, values that did not differ significantly $(P=0.45)$.

\section{DISCUSSION}

The present study demonstrates that chronic central OTR blockade during mid-late pregnancy significantly inhibits the enhanced expression of the SAHP in OT neurons, without affecting AHPs in VP neurons. This result suggests that enhancement of the sAHP may be one of the physiological mechanisms mediated by central OTR stimulation during midto late gestation, to ensure the normal release of systemic OT during labor and suckling by shaping OT bursting. Also, if the enhanced sAHP inhibits further firing of OT neurons for a period of several seconds after a train of action potentials, then it may contribute to the postburst inhibition observed during milk ejection (20). Thus this would ensure the short burst length optimal for bolus OT release in all neurons. The disrupted timing of OT release in response to suckling after
A Control Pregnant
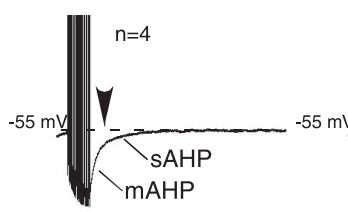

$$
\text { OTA Pregnant }
$$
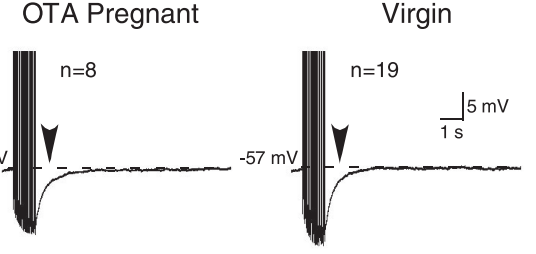

Superimposed
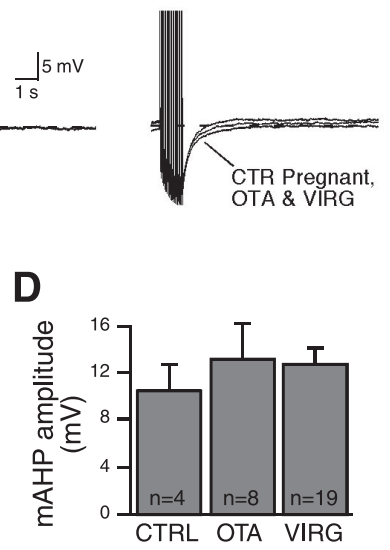

Fig. 3. AHPs in VP neurons. A: from left to right, the averaged traces of AHPs from VP neurons in control pregnant, pregnant receiving OTA, and virgin animals are shown, with each group superimposed at far right. AHPs were generated as described in Fig. 2. An abrupt deceleration in the decay of AHPs distinguishes mAHP and sAHP. Arrowheads indicate the location where sAHP amplitudes were measured. Unlike in OT neurons, neither the total area of the AHP $(B)$ nor the peak amplitude of the sAHP $(C)$ were higher during pregnancy or affected by the OTA. $D$ : the average amplitude of the mAHP in VP neurons also was not affected by pregnancy or by central blockade of the OTR.
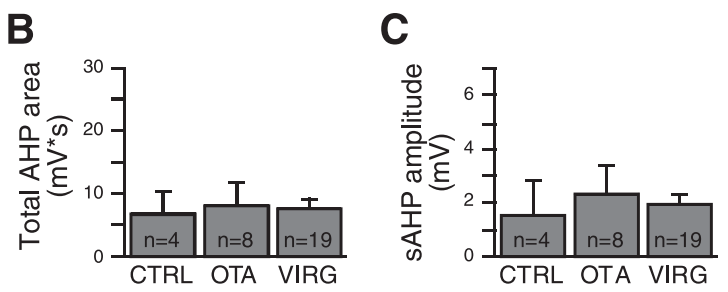

AJP-Endocrinol Metab • VOL 295 • NOVEMBER 2008 • www.ajpendo.org 
Fig. 4. Effect of apamin on AHPs in OT neurons. Some OT neurons from each group were treated with apamin $(100 \mathrm{nM})$, a blocker of small-conductance $\mathrm{K}^{+}(\mathrm{SK})$ channels mediating the mAHP, in order to isolate the SAHP. A: averaged traces of the isolated sAHP from OT neurons in control pregnant, OTA pregnant, and virgin rats. AHPs were generated as described in Fig. 2. $B$ : the area of the sAHP was significantly larger in OT neurons from control pregnant compared with those from OTA pregnant and virgin rats. Thus central blockade of OTR significantly attenuated the increased area of sAHP typically observed during pregnancy. $C$ : superimposed images of the traces before and after application of apamin for each experimental groups. Apamin suppressed the mAHP (arrowhead) in all cases. However, the area of the sAHP increased after application of apamin in OT neurons from control pregnant rats. Such increases in sAHP were not observed in OTA-treated pregnant or virgin rats. $D$ : the difference in the sAHP before and after apamin was significantly greater in control pregnant animals, but not in OTA-treated pregnant or virgin rats.
A

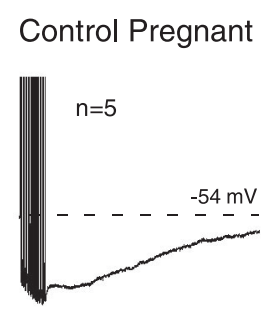

C

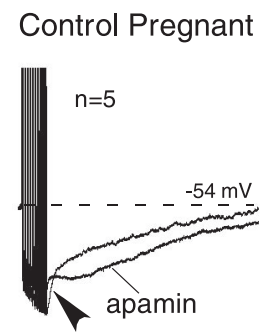

B
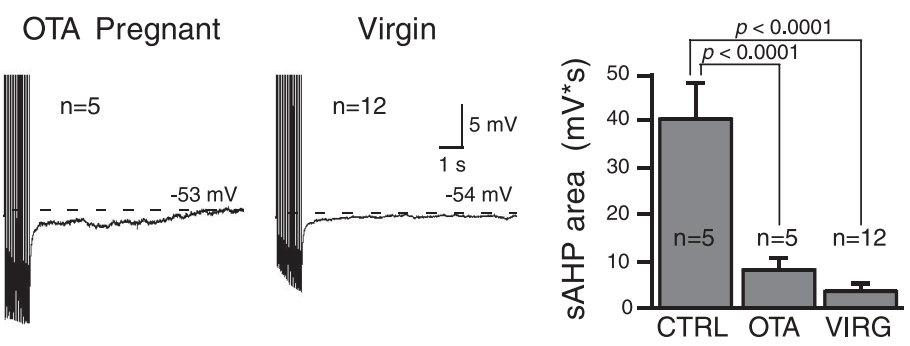

D

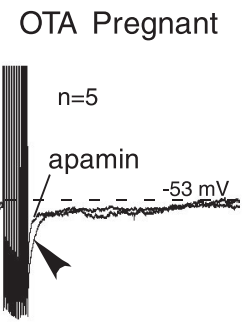

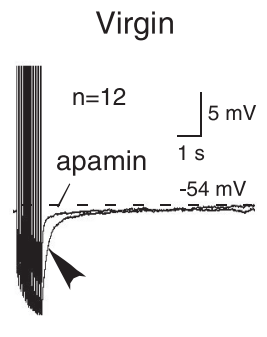

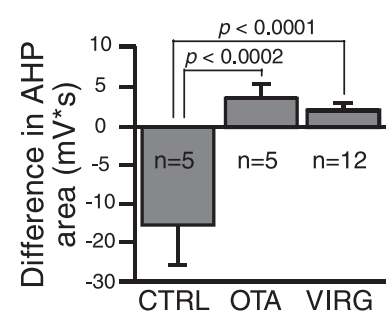

central infusion of a selective OTA during the final 2 wk of gestation (21) may be, at least partly, attributed to the absence of the enhanced sAHP.

The selective OTA we employed, desGly- $\mathrm{NH}_{2}-\mathrm{d}\left(\mathrm{CH}_{2}\right)^{5}[\mathrm{D}-$ $\mathrm{Tyr}^{2}, \mathrm{Thr}^{4} \mathrm{JOVT}$, is a competitive OTR antagonist, and its effects are reversed by OT both in vitro and in vivo (23). In the present study, the osmotic minipumps infusing the OTA were removed when the animals were killed for brain slice preparation and the brain slices were kept in medium devoid of the OTA for at least $3 \mathrm{~h}$ before the electrophysiological experiment. Moreover, acute (5-10 min) bath application of OTA to the brain slices had no effect on AHPs. Thus the effect of OTA we observed is likely due to the chronic subcellular changes mediated by central infusion of OTA during mid-late gestation rather than simple prolonged antagonism of OTR in the brain slices by this reversible antagonist. This interpretation is consistent with our previous finding (21) that the presence of this selective OTA specifically during pregnancy results in a longlasting delay in the release of OT during suckling. However, the exact mechanisms underlying these chronic effects are not known at present.

It is known that somato-dendritic secretion of OT within the SON is mediated by $\mathrm{Ca}^{2+}$-dependent exocytosis of large dense core vesicles $(22,32)$, a process that can be induced by as little as a single action potential in the SON neurons (12). This suggests that the OTR can be activated at the basal firing rate during the mid- to late gestation period when the OTR binding is significantly increased, even without an elevation in OT release (3). The OTR is a $\mathrm{G}$ protein-coupled receptor linked to the phospholipase C pathway (14), and the OT-induced rise in intracellular $\mathrm{Ca}^{2+}$ concentration $\left(\left[\mathrm{Ca}^{2+}\right]_{\mathrm{i}}\right)$ in OT neurons is due primarily to the release of $\mathrm{Ca}^{2+}$ from inositol 1,4,5-trisphosphate $\left(\mathrm{IP}_{3}\right)$-sensitive stores (11). It has also been reported recently that this OTRmediated intracellular release of $\mathrm{Ca}^{2+}$ evokes $\mathrm{Ca}^{2+}$ influx through specific store-operated channels in the plasma membrane in SON neurons (43). Considering that intracellular $\mathrm{Ca}^{2+}$ can be highly localized to subcellular microdomains, this allows cells to use the same messenger system to control a variety of cellular process including long-term modifications via regulation of gene transcription (5). In fact, through OTR, OT promotes cell proliferation and migration in endothelial cells in human dermal microvascular (8) and human umbilical vein (42) tissues. Furthermore, OT has been thought to play a role as trophic factor in the maturation of OT neurons during postnatal development $(9,10)$.

To our surprise, the area of the sAHP increased significantly in response to apamin, a blocker of the $\mathrm{Ca}^{2+}$-activated SK channels (35), in OT neurons from pregnant rats. More importantly, the enhancement of the sAHP was not observed in virgin or OTA-treated pregnant rats, which have relatively small sAHPs. This suggests that the increase in $\mathrm{Ca}^{2+}$ influx may increase the amplitude of the sAHP only if the system mediating the sAHP has been upregulated by the stimulation of OTR during pregnancy. To our knowledge, there is no report of this phenomenon in the literature, and it is unlikely that apamin directly enhances the sAHP. An alternative explanation may be that blockade of SK channels allows a stronger dendritic depolarization that may lead to further depolarization and $\mathrm{Ca}^{2+}$ influx. If so, we suggest that an enhanced $\mathrm{Ca}^{2+}$ influx, and perhaps the sAHP, are localized in the dendrites, since neither bulk $\left[\mathrm{Ca}^{2+}\right]_{i}$ nor highvoltage-activated $\mathrm{Ca}^{2+}$ currents are increased in the soma of lactating rats in response to apamin, despite an enhanced AHP during lactation (39). Moreover, the enhancement of sAHP during pregnancy and lactation may work through a $\mathrm{Ca}^{2+}$-dependent intermediary such as a second messenger system and/or coupling of the channels with a specific $\mathrm{Ca}^{2+}$ source. In this case, relatively small changes in the $\mathrm{Ca}^{2+}$ influx in the specific cytoplasmic microdomain may lead to a large difference in expression of the sAHP.

\section{ACKNOWLEDGMENTS}

The authors thank Dr. R. C. Foehring for reading earlier versions of this manuscript, Dr. M. Manning for the generous gift of OTA, and P. K. Tripathi for technical assistance. 


\section{GRANTS}

This study was supported by National Institute of Child Health and Human Development Grants R01-HD-038243 (S. L. Bealer), R01-HD-41002 (W. E. Armstrong), and NS-23941 (W. E. Armstrong).

\section{REFERENCES}

1. Armstrong WE, Smith BN, Tian M. Electrophysiological characteristics of immunochemically identified rat oxytocin and vasopressin neurones in vitro. J Physiol 475: 115-128, 1994.

2. Bealer SL, Crowley WR. Noradrenergic control of central oxytocin release during lactation in rats. Am J Physiol Endocrinol Metab 274: E453-E458, 1998.

3. Bealer SL, Lipschitz DL, Ramoz G, Crowley WR. Oxytocin receptor binding in the hypothalamus during gestation in rats. Am J Physiol Regul Integr Comp Physiol 291: R53-R58, 2006.

4. Belin V, Moos F, Richard P. Synchronization of oxytocin cells in the hypothalamic paraventricular and supraoptic nuclei in suckled rats: direct proof with paired extracellular recordings. Exp Brain Res 57: 201-203, 1984.

5. Berridge MJ. Neuronal calcium signaling. Neuron 21: 13-26, 1998.

6. Bicknell RJ. Optimizing release from peptide hormone secretory nerve terminals. J Exp Biol 139: 51-65, 1988.

7. Bourque CW, Brown DA. Apamin and D-tubocurarine block the afterhyperpolarization of rat supraoptic neurosecretory neurons. Neurosci Lett 82: 185-190, 1987.

8. Cassoni P, Marrocco T, Bussolati B, Allia E, Munaron L, Sapino A, Bussolati G. Oxytocin induces proliferation and migration in immortalized human dermal microvascular endothelial cells and human breast tumor-derived endothelial cells. Mol Cancer Res 4: 351-359, 2006.

9. Chevaleyre V, Dayanithi G, Moos FC, Desarmenien MG. Developmental regulation of a local positive autocontrol of supraoptic neurons. J Neurosci 20: 5813-5819, 2000.

10. Chevaleyre V, Moos FC, Desarmenien MG. Correlation between electrophysiological and morphological characteristics during maturation of rat supraoptic neurons. Eur J Neurosci 13: 1136-1146, 2001.

11. Dayanithi G, Sabatier N, Widmer H. Intracellular calcium signalling in magnocellular neurones of the rat supraoptic nucleus: understanding the autoregulatory mechanisms. Exp Physiol 85: 75S-84S, 2000.

12. de Kock CP, Wierda KD, Bosman LW, Min R, Koksma JJ, Mansvelder HD, Verhage M, Brussaard AB. Somatodendritic secretion in oxytocin neurons is upregulated during the female reproductive cycle. J Neurosci 23: 2726-2734, 2003.

13. Ghamari-Langroudi M, Bourque CW. Muscarinic receptor modulation of slow afterhyperpolarization and phasic firing in rat supraoptic nucleus neurons. J Neurosci 24: 7718-7726, 2004.

14. Gimpl G, Fahrenholz F. The oxytocin receptor system: structure, function, and regulation. Physiol Rev 81: 629-683, 2001.

15. Greffrath W, Martin E, Reuss S, Boehmer G. Components of afterhyperpolarization in magnocellular neurones of the rat supraoptic nucleus in vitro. $J$ Physiol 513: 493-506, 1998.

16. Hatton GI. Glial-neuronal interactions in the mammalian brain. $A d v$ Physiol Educ 26: 225-237, 2002.

17. Insel TR, Gingrich BS, Young LJ. Oxytocin: who needs it? Prog Brain Res 133: 59-66, 2001.

18. Kirkpatrick K, Bourque CW. Activity dependence and functional role of the apamin-sensitive $\mathrm{K}^{+}$current in rat supraoptic neurones in vitro. J Physiol 494: 389-398, 1996.

19. Landgraf R, Neumann I, Russell JA, Pittman QJ. Push-pull perfusion and microdialysis studies of central oxytocin and vasopressin release in freely moving rats during pregnancy, parturition, and lactation. Ann NY Acad Sci 652: 326-339, 1992.

20. Lincoln DW, Wakerley JB. Electrophysiological evidence for the activation of supraoptic neurones during the release of oxytocin. $J$ Physiol 242: 533-554, 1974

21. Lipschitz DL, Crowley WR, Bealer SL. Central blockade of oxytocin receptors during late gestation disrupts systemic release of oxytocin during suckling in rats. J Neuroendocrinol 15: 743-748, 2003.
22. Ludwig M. Dendritic release of vasopressin and oxytocin. $J$ Neuroendocrinol 10: 881-895, 1998.

23. Manning M, Miteva K, Pancheva S, Stoev S, Wo NC, Chan WY. Design and synthesis of highly selective in vitro and in vivo uterine receptor antagonists of oxytocin: comparisons with Atosiban. Int J Pept Protein Res 46: 244-252, 1995.

24. Montagnese C, Poulain DA, Theodosis DT. Influence of ovarian steroids on the ultrastructural plasticity of the adult supraoptic nucleus induced by central administration of oxytocin. J Neuroendocrinol 2: 225-231, 1990.

25. Montagnese CM, Poulain DA, Vincent JD, Theodosis DT. Structural plasticity in the rat supraoptic nucleus during gestation, post-partum lactation and suckling-induced pseudogestation and lactation. J Endocrinol 115: 97-105, 1987.

26. Moos F, Poulain DA, Rodriguez F, Guerne Y, Vincent JD, Richard P. Release of oxytocin within the supraoptic nucleus during the milk ejection reflex in rats. Exp Brain Res 76: 593-602, 1989.

27. Neumann I, Douglas AJ, Pittman QJ, Russell JA, Landgraf R. Oxytocin released within the supraoptic nucleus of the rat brain by positive feedback action is involved in parturition-related events. J Neuroendocrinol 8: 227-233, 1996.

28. Neumann I, Ludwig M, Engelmann M, Pittman QJ, Landgraf R. Simultaneous microdialysis in blood and brain: oxytocin and vasopressin release in response to central and peripheral osmotic stimulation and suckling in the rat. Neuroendocrinology 58: 637-645, 1993.

29. Neumann I, Russell JA, Landgraf R. Oxytocin and vasopressin release within the supraoptic and paraventricular nuclei of pregnant, parturient and lactating rats: a microdialysis study. Neuroscience 53: 65-75, 1993.

30. Neville MC. Physiology of lactation. Clin Perinatol 26: 251-279, 1999.

31. Poulain DA, Wakerley JB. Electrophysiology of hypothalamic magnocellular neurones secreting oxytocin and vasopressin. Neuroscience 7: 773-808, 1982.

32. Pow DV, Morris JF. Dendrites of hypothalamic magnocellular neurons release neurohypophysial peptides by exocytosis. Neuroscience 32: $435-$ 439, 1989.

33. Rasmussen KM, Warman NL. Effect of maternal malnutrition during the reproductive cycle on growth and nutritional status of suckling rat pups. Am J Clin Nutr 38: 77-83, 1983.

34. Richard P, Moos F, Freund-Mercier MJ. Central effects of oxytocin. Physiol Rev 71: 331-370, 1991.

35. Sah P, Faber ES. Channels underlying neuronal calcium-activated potassium currents. Prog Neurobiol 66: 345-353, 2002.

36. Schriefer JA, Lewis PR, Miller JW. Role of fetal oxytocin in parturition in the rat. Biol Reprod 27: 362-368, 1982.

37. Stern JE, Armstrong WE. Changes in the electrical properties of supraoptic nucleus oxytocin and vasopressin neurons during lactation. J Neurosci 16: 4861-4871, 1996.

38. Teruyama R, Armstrong WE. Changes in the active membrane properties of rat supraoptic neurones during pregnancy and lactation. J Neuroendocrinol 14: 933-944, 2002.

39. Teruyama R, Armstrong WE. Enhancement of calcium-dependent afterpotentials in oxytocin neurons of the rat supraoptic nucleus during lactation. J Physiol 566: 505-518, 2005.

40. Theodosis DT. Oxytocin-secreting neurons: a physiological model of morphological neuronal and glial plasticity in the adult hypothalamus. Front Neuroendocrinol 23: 101-135, 2002.

41. Theodosis DT, Chapman DB, Montagnese C, Poulain DA, Morris JF. Structural plasticity in the hypothalamic supraoptic nucleus at lactation affects oxytocin-, but not vasopressin-secreting neurones. Neuroscience 17: 661-678, 1986.

42. Thibonnier M, Conarty DM, Preston JA, Plesnicher CL, Dweik RA, Erzurum SC. Human vascular endothelial cells express oxytocin receptors. Endocrinology 140: 1301-1309, 1999.

43. Tobin V, Gouty LA, Moos FC, Desarmenien MG. A store-operated current (SOC) mediates oxytocin autocontrol in the developing rat hypothalamus. Eur J Neurosci 24: 400-404, 2006. 